sternidæe, in which they form the subfamily Staurotypinæ. Mr. Siebenrock goes, however, even further than this, and suggests that the Cinosternidæ should be brigaded with the Chelydridæ in one sectional group-the Chelydroidea; while the families Dermatemydidæ and Platysternidæ are regarded as more nearly related to the Testudinidæ, with which they should form the group Testudinoidea. For the structural details on which the author justifies this radical change in taxonomy, reference must be made to the paper itself.

Morphologists will find much to interest them in an article in the same volume by Mr. Max Holl, of Graz, on the anatomy of the hind portion of the cerebral lobes in man and apes. The author appears to have been led to undertake the investigation by finding one human brain which differed most remarkably in regard to the arrangement and complexity of the postero-lateral sulci from all others which had come under his observation. His studies have, however, shown that there is a great amount of variation in this respect in human brains, and he has in consequence been led to recognise two principal types. To the more primitive of these he gives the name pithecoid and to the other that of anthropoid, type. Between the two there exists, however, an almost complete gradation. By far the greatest degree of individual variation in the form of the postero-lateral region of the brains of Primates occurs in the case of the tropical American spider-monkeys of the genus Ateles.

Attention may likewise be directed to a paper by $\mathrm{Dr}$. Karl Byloff in the same volume on the structure and lifehistory of the blood-parasites Trypanosoma lewisi and $T$. brucei. New methods of staining microscopic preparations have enabled the author to bring to light certain previously unknown features in connection with these organisms. The various developmental stages assumed by trypanosomes in mammalian blood are the result of division of adult forms. High magnifying power has revealed the presence of pseudopodia-like projections at the "hind extremity" of both species of trypanosomes, but whether these are constant morphological features or merely temporary developments has yet to be demonstrated.

\section{THE CENTENARY OF DAVY'S DISCOVERY} OF THE METALS OF THE ALKALIS. ${ }^{1}$

A HUNDRED years ago last October, there happened one of those events to which the term epoch-making may, without cavil or question, be fittingly applied.

As it was an occurrence with which the name and fame of the Royal Institution are inseparably bound up, the managers have thought it only proper that its centenary should not pass unnoticed here, and it is by their wish, therefore, that I appear on this the first possible opportunity after the actual date of its hundredth anniversary to give you some account of it, and to state, so far as I am able and within the limits of an hour, the fruitful consequences that have flowed from it.

Let me, in the first place, attempt to recall the circumstances which led up to that cardinal discovery of which to-night we celebrate the centenary. These are connected partly with the institution itself and partly with the state of science in the early yeirs of the nineteenth century.

In the year 1807 this institution was entering upon the eighth year of its existe ce. As you doubtless know, the Royal Institution grew out of a proposal to deal with the question of the unemployed, namely, by forming in London by private subscription an establishment for feeding the poor and giving them useful employment, and also for furnishing food at a cheap rate to others who may stand in need of such assistance, connected with an institution for introducing and bringing forward into general use new inventions and improvements, particularly such as relate to the management of heat and the saving of fuel, and to various other mechanical contrivances by which domestic comfort and economy may be promoted. Such was the original prospectus, but, like many other prospectuses, it failed to equal the promise its projectors held out.

'I A lecture delivered at the Royal Incti 1 ution of Great Britain, on Friday, January 17 , by Prof. T. E. Thorpe, C. B., F.R.S.

NO. I 996 , vOL. 777
Eventually the promoters decided, on the initiation of Count Rumford, that the Associated Institution would, as they expressed it, be " too conspicuous and too interesting and important to be made an appendix to any other existing establishment," and therefore it ought to stand alone on its own proper basis.

Accordingly, the problem of the unemployed still remains with us, whilst the new institution took the form of converting Mr. Mellish's house in Albemarle Street into a place where, by regular courses of philosophical lectures and experiments, the applications of the new discoveries in science to the improvement of the arts and manufactures might be taught, so as to facilitate the means of procuring the comforts and conveniences of life.

The Royal Institution had a troubled infancy. Like the poor it was originally designed to succour, it suffered much in the outset from lack of nourishment. To add to its miseries, the little starveling was caricatured by Gillray, lampooned by Peter Pindar, and ridiculed by Lord Brougham, and it was literally in the throes of dissolution when new life was breathed into it by the opportune arrival, in $180 \mathrm{I}$, of a small spare youth of twenty-two from Bristol, whom the managers had engaged at a salary of 100 guineas a year. The youth was Humphry Davy, who had acted as assistant to Dr. Beddoes, of the Pneumatic Institution, and who had already made some slight stir in scientific circles by his discovery of a characteristic property of nitrous oxide. In announcing his arrival to the managers, Count Rumford reported that he had purchased a cheap second-hand carpet for Mr. Davy's room, together with such other articles as appeared to him necessary to make the room habitable, and among the rest a new sofa-bed, which, in order that it may serve as a model for imitation, had been made complete in all its parts. Six weeks after his arrival Davy was called upon to lecture, and a descriptive paragrapher of the period thus chronicles his success in the Philosophical Magazine for I80x :-

"It must give pleasure to our readers to learn that this new and useful institution, the object of which is the application of Science to the common purposes of life, may be now considered as settled on a firm basis. .

"We have also to notice a course of lectures, just commenced at the institution, on a new branch of philosophy -we mean the Galvanic Phenomena. On this interestings branch, Mr. Davy (late of Bristol) gave the first lecture on the $25^{\text {th }}$ of April. He began with the history of Galvanism, detailed the successive discoveries, and described the different methods of accumulating galvanic influence. . . . $\mathrm{He}$ showed the effect of galvanism on the legs of frogs, and exhibited some interesting experiments on the galvanic effects on the solution of metals in acids. Sir Joseph Banks, Count Rumford, and other distinguished philosophers were present. The audience were highly gratified, and testified their satisfaction by general applause. Mr. Davy, who appears to be very young, acquitted himself admirabiy well: from the sparkling intelligence of his eye, his animated manner, and the tout ensemble, we have no doubt of his attaining a distinguished eminence."

And what was of more immediate consequence, this confident assurance was shared also by the managers, for at a subsequent meeting they unanimously resolved " that $\mathrm{Mr}$ Humphry Davy director of the chemical laboratory, having given satisfactory proofs of his talents as a lecturer, should be appointed, and in future denominated. lecturer in chemistry at the Royal Institution, instead of continuing to occupy the place of assistant lecturer, which he has hitherto filled."

That such shrewd experienced men of the world as Sir Ioseph Banks and Rumford, who were the moving spirits in the management of the institution and genuinely solicitous for its welfare, should thus entrust its fortunes, then at their lowest ebb, to the power and ability of a young and comparatively unknown man, barely out of his teens, seems, even in an age which was familiar with the spectacle of " a proud boy" as a Prime Minister, like the desperate throw of a gambler.

But Banks and Rumford had, doubtless, good reason for the faith that was in them. For a happv combination of circumstances had served to bring the Cornish youth within the range of many who could be of service to him in that search for the fame for which he hungered. His 
connection with the Beddoes brought him the friendship of the Edgeworths, and it is amusing to trace how the good-humoured patronage of the gifted Maria quickly passed into amazement and ended in awe as her acquaint ance with him ripened. Living in $\mathrm{Br}^{-1}$ stol, he was at once brought into that remarkable literary coterie which distinguished that city at the close of the eighteenth century. Southey spoke of him as a miraculous young man, whose talents he could only wonder at. Cottle, the publisher, on one occasion said to Coleridge, "You have doubtless seen a great many of what are called the cleverest nien-how do you estimate Davy in comparison with these?" Mr. Coleridge's reply was strong and expressive. "Why, Davy can eat them all! There is an energy, an elasticity, in his mind which enables him to seize on and analyse all questions, pushing them to their legitimate consequences. Every subject in Davy's mind has the principle of vitality. Living thoughts spring up like turf under his feet."

Davy's experimental work on "the pleasure-giving air" had made him known to the Watts and the Wedgwoods. Priestley, then in exile, and Hope, of Edinburgh, were greatly impressed with the philosophical acumen of the author of phosoxygen, and he had a powerful friend in his own countyman Davies Gilbert, who succeeded him in the presidential chair of the Royal Society. We need be in no doubt, therefore, as to the influences which conspired to bring Davy into what he termed "the great hotbed of human power called London."

The mention of Davy's first course of lectures in this institution brings me at once to the proper subject of this discourse.

The first year of the last century is memorable for the invention of the voltaic battery and for its immediate application by Nicholson and Carlisle in this country to the electrolytic decomposition of water.

Davy himself has said:- "The voltaic battery was an alarm bell to experimenters in every part of Europe; and it served no less for demonstrating new properties in electricity, and for establishing the laws of this science, than as an instrument of discovery in other branches of knowledge; exhibiting relations between subjects before apparently without connection, and serving as a bond of unity between chemical and physical philosophy."

We owe it to Sir Joseph Banks that Volta's great discovery was first made known to English men of science, and the study of the phenomena of galvanic electricity was at once entered upon by a score of experimenters in this country. Among them was Davy. Even before he left Bristol he was hard at work on the subject, sending the results of his observations to Nicholson's Journal in a series of short papers. $\mathrm{He}$ resumed his inquiries immediately on his arrival in London, and was doubtless well prepared, therefore, for his opening course of lectures.

In $180 \mathrm{r}$ he sent his first communication to the Royal Society on "An Account of some Galvanic Combinations formed by the Arrangement of Single Metallic Plates and Fluids, Analogous to the New Galvanic Apparatus of $\mathrm{Mr}$. Volta." Although the work was continually interrupted by requests made to him by the managers to carry out their own ideas of facilitating the means of procuring the comforts and conveniences of life, he never lost sight of the subject of voltaic electricity, and in spite of innumerable distractions die to the precarious position of the institution, he gradually accumulated the material out of which grew his first Bakerian lecture, "On some Chemical Agencies of Electricity," read before the Royal Society on November 20, 1806. I have ventured elsewhere to express my opinion of this paper. In my judgment it constitutes, in reality, Davy's greatest claim as a philosopher to our admiration and gratitude, for in it he, for the first time, succeeded in unravelling the fundamental laws of electrochemistry, and thereby imported a new order of conceptions, altogether unlooked for and undreamt of, into science.

I am only at the moment concerned with this memoir in its relation to the discovery of which to-night we celebrate the centenary. The isolation of the metals of the alkalis was unquestionably an achievement of the highest brilliancy and as such appeals strongly to the popular imagination. But it was only the necessary and consequential link in a chain of discovery which, had Davy neglected to make it, would have been immediately forged by another.

The publication of Davy's first Bakerian lecture produced a great sensation, both at home and abroad. Berzelius, years afterwards, spoke of it as one of the most remarkable memoirs that had ever enriched the theory of chemistry. Very significant, too, of the impression it made on the world of science was the action of the French Institute. Bonaparte, then First Consul, had announced his intention of founding a medal "for the best experiment which should be made in the course of each year on the galvanic fluid," and a committee of the institute, consisting of Laplace, Halle, Coulomb, Hauy, and Biot, was appointed to consider the best means of giving effect to the wishes of the First Consul. To the young man, with the little brown head, like a boy (as Lady Brownrigg described him), now twenty-eight years of age, was awarded the medal. All the institute got from the founder of the medal was what Maria Edgeworth termed "a rating all round in imperial Billingsgate." There was no entente cordiale in those days; indeed, the feeling of animosity was intense. Of course, there were persons who said that patriotism should forbid the acceptance of the award. Davy's own view was more sensible and politic:- "Some people," he said to his friend Poole, " say I ought not to accept this prize; and there have been foolish paragraphs in the papers to that effect; but if the two countries or Governments are at war, the men of science are not. That would, indeed, be a civil war of the worst description; we should rather, through the instrumentality of men of science, soften the asperities of national hostility."

Thanks to the kindness of Dr. Humphry Davy Rolleston, the grandson of Dr. John Davy, the brother of Sir Humphry, who has also been so good as to lend me this admirable bust of the great chemist by Chantrey, and this charming portrait by Jackson, I am able to show you this evening this historically interesting medal.

What Davy looked like at this period of his life may be seen from the picture I now project upon the screen. It is a reproduction of the large portrait which hangs in the vestibule, and which the institution owes to the thoughtful kindness of the late Mr. Graham Young.

As the applications of voltaic electricity seemed in 1806 to have no immediate bearing on the comforts and conveniences of life, Davy, during the greater part of the following year, was required to direct his attention to other matters. But in the late summer of 1807 he was able to resume his work with the voltaic battery, and he commenced to study its action on the alkalis.

That the alkalis-potash and soda-would turn out to be compound substances was not an unfamiliar idea at the time, and it is significant that almost immediately after Nicholson and Carlisle had resolved water into its elements by the action of voltaic electricity, Henry, of Manchester, the friend and collaborator of Dalton, should have made the attempt to apply the same agency to the separation of the presumed metallic principle of potash. The conception that what the older chemists called " earths" might be made to yjeld metals was at least as old as the time of Boyle, and probably dates back from the earliest days of alchemy. The relation of the earths to the metals was part of the doctrine of Becher and Stahl; it was no less a part of the antiphlogistic doctrine of Lavoisier, although the points of view were diametrically opposed. Neumann attempted to obtain a metal from lime, Bergman considered that baryta was, like lime, a metallic calx, and Baron that alumina contained a metal. From their many analogies to these substances it was not unreasonable, therefore, to surmise that potash and soda might also contain metallic principles.

I have elsewhere pointed out that there is some evidence that whilst at Bristol Davy had already attacked the problem of the resolution of the alkalis by means of voltaic electricity. What precise idea he had in again attacking it, or what expectation he had of a definite result, is difficult to determine. In one of his lectures on electrochemical science, delivered some time subsequently, he said he had a suspicion at the time that potash might turn out to be " phosphorus or sulphur united to nitrogen," 
conceiving that, as the volatile alkali was composed of the light inflammable hydrogen united to nitrogen, so the fixed and denser alkalis might be composed of the denser inflammable bodies-phosphorus and sulphur-also united to nitrogen.

Davy once said that " analogy was the fruitful parent of error," and few more striking instances of perverted analogy are to be met with in science than this. In another of his lectures he said of the alchemists that " even their failures developed some unsought-for object partaking of the marvellous"; and if such had been his reasoning, the statement is no less true of himself.

So far as can be ascertained, it was on October I9, $180 \tau$, that he obtained his first decisive result. This is thus described in Davy's own handwriting in the Laboratory Journal, which has been preserved for us by the pious care of Faraday, and which is one of the most precious of the historical possessions of the Royal Institution :"When potash was introduced into a tube having a platina wire attached to it, so [fig.], and fused into the tube so as to be a conductor-i.e. so as to contain just water enough, though solid-and inserted over mercury, when the platina was made negative, no gas was formed and the mercury became oxydated, and a small quantity of the alkaligen was produced round the platina wire, as was evident from its quick inflammation by the action of water. When the mercury was made the negative, gas was developed in great quantities from the positive wire, and none from the negative mercury, and this gas proved to be pure oxygen - a capital experiment, proving the decomposition of potash." On the 19th of the following month he delivered what is generally regarded as the most memorable of all his Bakerian lectures. It is entitled " On some New Phenomena of Chemical Changes produced by Electricity, Particularly the Decomposition of the Fixed Alkalies; and the Exhibition of the New Substances which Constitute their Bases; and on the General Nature of Alkaline Bodies."

Few discoveries of like magnitude have been made and perfected in so short a time, and few memoirs have been more momentous in result than that which, put together in a few hours, gave the results of that discovery to the world.

The whole work was done under conditions of great mental excitement. His cousin, Edmund Davy, who at the time acted as his assistant, relates that when he saw the minute globules of the quicksilver-like metal burst through the crust of potash and take fire, his joy knew no bounds; he actually danced about the room in ecstasy and it was some time before he was sufficiently composed to continue his experiments.

The rapidity with which he accumulated results after this first feeling of delirious delight had passed was extraordinary, and he had obtained most of the leading facts concerning the physics and chemistry of the new substances before the middle of November.

$\mathrm{He}$ began his lecture with a felicitous reference to the concluding remarks of the one of the previous year namely, "That the new methods of investigation promised to lead to a more intimate knowledge than had hitherto been obtained concerning the true elements of bodies. This conjecture, then sanctioned only by strong analogies, I am now happy to be able to support by some conclusive facts.'

In the first attempts he made to decompose the fixed alkalis he acted upon concentrated aqueous solutions of potash and soda with the highest electrical power he could then command at the Royal Institution, viz. from voltaic batteries containing twenty-three plates of copper and zinc of 12 inches square, 100 plates of 6 inches, and 150 of 4 inches, charged with solutions of alum and nitric acid but although there was high intensity of action, nothing but hydrogen and oxygen was disengaged. $\mathrm{He}$ next tried potash in igneous fusion, and here the results were more encouraging; there were obvious and striking signs of decomposition; combustible matter was produced, accompanied with flame and a most intense light. $\mathrm{He}$ had observed that although potash, when dry, is a non-conductor, it readily conducts when it becomes damp by exposure to air, and in this state "fuses and decomposes by strong electrical powers."

No. I 996, vOL. 777
Let me state in his own words, for the words are classical, what followed :-

"A small piece of pure potash, which had been exposed for a few seconds to the atmosphere, so as to give conductive power to the surface, was placed upon an insulated disc of platina, connected with the negative side of the battery of the power of $25^{\circ}$ of 6 and 4 [that is 100 plates of 6 inches square and 150 plates of 4 inches square] in a state of intense activity; and a platina wire communicating with the positive side was brought in contact with the upper surface of the alkali. . . Under these circumstances a vivid action was soon observed to take place. The potash began to fuse at both its points of electrization. There was a violent effervescence at the upper surface; at the lower, or negative surface, there was no liberation of elastic fluid; but small globules, having a high metallic lustre, and being precisely similar in visible characters to quicksilver, appeared, some of which burnt with explosion and bright flame, as soon as they were formed and others remained, and were merely tarnished, and finally covered by a white film which formed on their surfaces.'

He goes on to say :-

"Soda, when acted upon in the same manner as potash, exhibited an analogous result; but the decomposition demanded greater intensity of action in the batteries, or the alkali was required to be in much thinner and smaller pieces.

"The substance produced from potash remained fluid at the temperature of the atmosphere at the time of its production; that from soda, which was fluid in the degree of heat of the alkali during its formation, became solid on cooling, and appeared having the lustre of silver."

It would seem from this description of its properties that the potassium Davy first obtained was alloyed with sodium owing to the fact that the potash contained soda. Potassium is solid up to $143^{\circ} \mathrm{F}$., whereas, as Davy was the first to show, an alloy of potassium and sodium is fluid at ordinary temperatures.

On account of their alterability in contact with air Davy had considerable difficulty in preserving and confining the new substances so as to examine their properties. As he says, like the alkahests imagined by the alchemists, they acted more or less upon almost every body to which they were exposed. Eventually, he found they might be preserved in mineral naphtha.

The "basis" of potash was described by him as a soft malleable solid with the lustre of polished silver.

"At about the freezing point of water it becomes harder and brittle, and when broken in fragments, exhibits a crystallised texture which in the microscope seems composed of beautiful facets of a perfect whiteness and high metallic splendour. It may be converted into vapour below a red heat, and may be distilled unchanged, and is a perfect conductor of heat and electricity. Its most marked difference from the common run of metals is its extraordinary low specific gravity." At the time of its discovery it was the lightest solid known.

The "basis" of soda was found to have somewhat similar properties. It was slightly heavier than the "basis" of potash, and fused at a higher temperature.

Davy next examined the behaviour of the new substances towards a large number of reagents, but as his observations are now the common property of the textbooks, it is unnecessary here to dwell upon them.

$\mathrm{He}$ then enters upon some general observations on the relations of the "bases" of potash and soda to other bodies :-

"Should the bases of potash and soda be called metals? The greater number of philosophical persons," he says, "to whom this question has been put, have answered in the affirmative. They agree with metals in opacity, lustre, malleability, conducting powers as to heat and electricity, and in their qualities of chemical combination.

"Their low specific gravity does not appear a sufficient reason for making them a new class; for amongst the metals themselves there are remarkable differences in this respect. . In the philosophical division of the classes of bodies, the analogy between the greater number of properties must always be the foundation of arrangement. 
"On this idea, in naming the bases of potash and soda, it will be proper to adopt the termination which by common consent has been applied to other newly discovered metals, and which, though originally Latin, is now naturalised in our language.

"Potasium (sic) and sodium are the names by which I have ventured to call the new substances; and whatever changes of theory, with regard to the composition of bodies, may hereafter take place, these terms can scarcely express an error; for they may be considered as implying simply the metals produced from potash and soda. I have consulted with many of the most eminent scientific persons in this country upon the methods of derivation, and the one I have adopted has been the one most generally approved. It is perhaps more significant than elegant. But it was not possible to found names upon specific properties not common to both; and though a name for the basis of soda might have been borrowed from the Greek, yet an analogous one could not have been applied to that of potash, for the ancients do not seem to have distinguished between the two alkalies."

Such, then, are the more significant features of one of the greatest discoveries ever made by a British chemist, as these are set forth in one of the most remarkable papers in the Philosophical Transactions of the Royal Society.

The publication of Davy's discovery created an extraordinary sensation throughout the civilised world, a sensation not less profound, and certainly more general from its very nature, than that which attended his lecture of the previous year. But at the very moment of his triumph it seemed that the noise of the universal acclaim with which it was received was not to reach him. I have already made reference to the condition of mental excitement under which the discovery was made and prosecuted. Almost immediately after the delivery of his lecture he collapsed, struck down by an illness which nearly proved fatal, and for weeks his life hung on a thread. He had been in a low, feverish condition for some time previously, and a great dread had fallen upon him that he should die before he had completed his discoveries. It was in this condition of body and mind that he had applied himself to the task of putting together an account of his results. Four days after this was given to the world he took to his bed, and he remained there for nine weeks. Such a blow following hard on the heels of such a triumph aroused the liveliest sympathy. The doors of the Royal Institution were beset by anxious inquirers, and written reports of his condition at various periods of the day had to be posted in the hall. The strength of the feeling may be gleaned, too, from the sentences with which the Rev. Dr. Dibdin, who had been hurriedly engaged to take his place in the theatre, began the lecture introductory to the session of 1808 :-.

"The managers of this institution have requested me to impart to you that intelligence, which no one who is alive to the best feelings of human nature can hear without the mixed emotion of sorrow and delight.

" $\mathrm{Mr}$. Davy, whose frequent and powerful addresses from this place, supported by his ingenious experiments, have been so long and so well known to you, has, for the last five weeks, been struggling between life and death. The effects of these experiments recently made in illustration of his late splendid discovery, added to consequent bodily weakness, brought on a fever so violent as to threaten the extinction of life. Over him it might emphatically be said in the language of our immortal Milton, that

\section{'. . Death his dart}

Shook, but delayed to strike."

"If it had pleased Providence to deprive the world of all further benefit from his original talents and intense application, there has certainly been sufficient already effected by him to entitle him to be classed among the brightest scientific luminaries of his country."

After having, " at the particular request of the managers," given an outline of Davy's investigations, Dr. Dibdin proceeded to say :-

"These may justly be placed among the most brilliant and valuable discoveries which have ever been made in chemistry, for a great chasm in the chemical system has been filled up; a blaze of light has been diffused over that part which before was utterly dark; and new views have been opened, so numerous and interesting, that the more any man who is versed in chemistry reflects on them, the more he finds to admire and heighten his expectation of future important results.

Mr. Davy's name, in consequence of these discoveries, will be always recorded in the annals of science amongst those of the most illustrious philosophers of his time. His country, with reason, will be proud of him, and it is no small honour to the Royal Institution that these great discoveries have been made within its walls-in that laboratory, and by those instruments which, from the zeal of promoting useful knowledge, have, with so much propriety, been placed at the disposal and for the use of its most excellent professor of chemistry."

And now, in the few minutes that remain to me, let me indicate what has been the outcome of this great and fundamental discovery. How far has the expectation of future important results been realised? Have sodium and potassium at all justified the hope that they would facilitate the means of procuring the comforts and conveniences of life?

I have not the time, even if I had the intention, to attempt to follow the many changes in the metallurgy of the metais of the alkalis of the past century. Let me at once proceed to show how the matter stands at the end of a hundred years.

The general properties and chemical activities of potassium and sodium are so very similar that, as a matter of commercial production, that metal which can be most economically obtained is necessarily the one most largely manufactured, and of the two that metal is sodium. To-day, sodium is made by thousands of tons, and by a process which in principle is identical with that by which it was first made by Davy, i.e. by the electrolysis of fused caustic soda. It is very significant that after a series of revolutions in its manufacture, sodium, having been produced from time to time on a manufacturing scale by a variety of metallurgical methods involving purely thermal processes of reduction and distillation, entirely dissociated from electricity, we should have now got back to the very principle of the process which first brought the metal to light. And that this has been industrially possible is entirely owing to another of Davy's discoveries-possibly indeed the greatest of them all-Michael Faraday. As we all gratefully acknowledge, it is to the genius and labours of Faraday-Davy's successor in this place-that the astonishing development of the application of electrical energy which characterises this age has taken its rise.

The modern method of production of sodium is based, therefore, as regards principles, upon the conjoint labours of Davy and Faraday.

These principles took their present form of application at the hands of a remarkably talented American- $\mathrm{Mr}$. Hamilton Y. Castner-whose too early death, in the full vigour of his intellectual powers, was an incalculable loss to metallurgical chemistry. It is by Castner's process that all the sodium of to-day is manufactured.

In the Castner process melted caustic soda, produced by the electrolysis of a solution of common salt by a method also devised by Castner, is brought into an iron vessel shaped like a large cauldron, mounted in brickwork, and provided with an extension adapted to receive the negative electrode. Suspended directly above the kathode is an iron vessel attached to a lid; to its lower edge is secured iron wire gauze, which, when the receptacle is in position, completely surrounds the kathode. The positive electrode is connected with the lid of the vessel, which is provided with openings for the escape of the gases resulting from the electrolysis, and is suitably insulated.

As the electrolysis proceeds, the alkali metal, being much lighter than the molten caustic, rises from the negative electrode and passes into the receiver, the gases escaping around the edges of the cover. The molten metal collects on the surface of the caustic, and is removed by means of a large perforated spoon, the perforations enabling the melted caustic to flow out, while the metal remains in the spoon. As the several vessels are thus skimmed in succession, the fused sodium is collected into an iron vessel, whence it is poured into moulds in which

No. 1996, voL. 74$]$ 
it congeals, forming blocks of the size and shape of an ordinary building brick. These, after being trimmed to remove adherent oxide, are immersed in paraffin oil, and are then packed into large iron drums holding about 6 cwt. or $7 \mathrm{cwt}$., capable of being closed air-tight, and protected in transit by an outer casing of wood.

The due regulation of the volume and intensity of the current is a matter of the greatest importance in order to obtain the most economical yield of the metal. No very high temperature is needed; indeed, the temperature of the fused caustic soda should not be much higher than that of its melting point. By suitably regulating the current, the soda, in fact, may be maintained at the proper temperature and in the proper degree of fluidity without extraneous heat. Fresh melted caustic soda is added to the vessel from time to time to replace the metal removed, and in this manner the process is made continuous.

The Castner process is now worked in England at Wallsend-on-Tyne, and at Weston Point, in Cheshire; at Rheinfelden, in Germany; at Clavaux, in France; also in Switzerland, and at Niagara, in America. The present yearly output amounts to about 5000 tons, but the plant already laid down is capable of producing at least twice this quantity.

The greater quantity of the sodium made in England is sent to Glasgow, where it is converted into sodium ryanide by the Cassel Cyanide Company for use in the extraction of gold. As gold is, I suppose, generally considered the principal material factor in procuring the comforts and conveniences of life, Davy's great discovery may be thus said to have secured the primary object which the projectors of the Roval Institution had in view. Other important uses of sodium are in the manufacture of peroxide for bleaching purposes, of artificial indigo, and of a number of other synthetic dye-stuffs and of drugs like antipyrin.

It need hardly be said that this extraordinary development of the manufacture has not been without its influence on the price of sodium. A quarter of a century ago it was a comparatively rare metal, and a stick of it was regarded as a chemical curiosity, to be handled with circumspection and care. Even as late as 1890 its selling price was as high as $8 s$. per $1 \mathrm{~b}$. To-day it is $8 d$. Sodium now takes rank, therefore, with zinc, tin, copper, or aluminium as a common, ordinary metal of commerce.

I am indebted to the directors of the Castner-Kellner Company, and in particular to my friends Sir Henry Roscoe and Mr. Beilby, for affording me the opportunity, in connection with this lecture, of actually witnessing the modern process of manufacturing sodium as it is carricd out at Wallsend, and I am further indebted to Mr. Beilby for the loan of the lantern-slides and specimens with which I have sought to illustrate that process.

And in concluding may I be permitted to recall here the feelings to which that visit to Wallsend gave rise? There, grouped together on the very spot where ended the old wail - the visible symbol of the power and might of a civilisation long since passed away-were some of the characteristic signs of another civilisation ampler and more beneficent. Before me, stretching down to the river, was the factory where a score of workers, clad in helmets and gauntlets, and swathed like so many Knights Templar, thei visages lit up by the yellow soda flames, and their ear half-deafened with the sound of exploding hydrogen-a veritable inferno-were repeating on a Gargantuan scale the little experiment first made a century ago in the cellars of this building, turning out, day and night, tons of the plastic metal in place of the little pin-heads which then burst upon the astonished and delighted gaze of Davy. Behind me was the magnificent power-house-one of the most magnificent of its kind in the world-furnishing not only the electrical energy which transformed the soda into sodium, but diffusing this energy for a multitude of other purposfs over an entire district-a noble temple to the genius and prescience of Faradav. Surely one might here say, if you desire to see the monuments of these men, look around 1 And to my right, and close at hand, was the huge building slip just vacated by the Mauretania, herself a symbol of the supremacy of an empire, far mightier. more world-wide, and more potent for good than that which massed its legions behind the old wall.

No. I 996, VOL. 77]

\section{UNIVERSITY AND EDUCATIONAL INTE LLIGENCE}

Cambridge.--The electors to the Allen scholarship give notice that they are prepared to receive applications from candidates. Any graduate of the University is eligible for the scholarship provided that his age on the first day of the Lent term 1908 does not exceed twenty eight years. This year the scholarship is open to candidates who propose to undertake research in any branch of study which comes within the department of any of the following special boards:--medicine, mathematics, physics and chemistry, biology and geology. The scholarship is tenable for one year, during which period it will be the duty of the student to devote himself to research in Cambridge or elsewhere. The emolument of the student is $250 l$., or such smaller sum as the fund, after payment of all expenses, shall be capable of providing. Every candidate must send particulars of his qualifications, \&.e., to the Vice-Chancellor, Gonville and Caius College Lodge, on or before February 15.

Manchester.-..The following brief summary of some recently published statistics serves to illustrate the development in the work of the University during the past eight years. The table not only indicates that a considerable increase has taken place in the numbers of students and staff, but also shows that the progress has been particularly marked in the fields of advanced study and research. The growing success of the honours schools in both science and arts is particularly worthy of notice:-

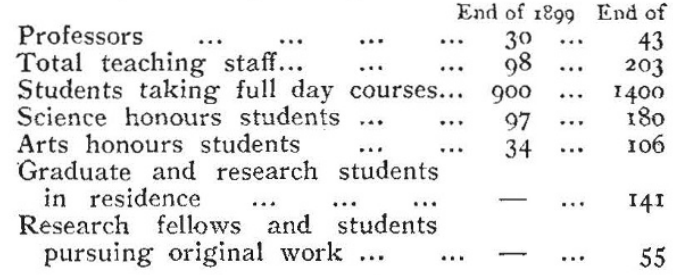

By the will of the late Mr. Basil McCrea, the Magee Presbyterian College, Londonderry, receives several substantial benefactions. Among these gifts occur 14,00ol. for building and equipping a new lecture hall; a sum to endow two professorships, to be known respectively as the "Henry Wallace" and the "William Archer Butler" professorships, each professor to receive an annual stipend of $300 l$; ; a sum to found and endow two lectureships in the science department of the college, each lecturer to receive an annual stipend of $150 l$. and to be known as the "McCrea lecturers"; such annual sum as may be necessary to make up the stipends of each of the professorships in the literary and science departments to $300 l$. per annum; $500 l$. each ycar to found and endow a "McCrea science scholarship" and a "McCrea literary scholarship," each of the value of $100 l$, to be competed for every third year, and any surplus to be used for " McCrea prizes " in the science and literary departments.

AT a recent meeting of the governors of the Glasgow and West of Scotland Technical College it was intimated that the Glasgow City Educational Endowments Board had made a further grant of roool, to the building fund of the college, and that the trustees of the Bellahouston Bequest Fund had promised a donation of $5000 \mathrm{l}$. on condition that the governors raised a further sum of $45,000 l$. Including these grants, the building fund now amounts to $30 \mathrm{r}, \mathrm{oool}$. The governors of the college have just resolved to raise the standard of the preliminary examination for admission to the course for the college diploma to that of the Leaving Certificate of the Scotch Education Department. The holders of this certificate are exempted from the preliminary examination of the Scottish universities. This raising of the standard of the entrance examination by the governors of the great technical college at Glasgow represents a new departure of high significance in technical education. Now that the courses will be based upon a preparatory training equal to that demanded by any British university, it will be possible to make substantial advance in the quality of the work undertaken. 